Article

\title{
Evaluation of the Zone of Influence and Entrainment Impacts for an Intake Using a 3-Dimensional Hydrodynamic and Transport Model
}

\author{
Shwet Prakash ${ }^{1}$, Venkat Kolluru ${ }^{1, *}$ and Carol Young ${ }^{2}$
}

1 Pennsylvania Office, Environmental Resources Management (ERM) Inc., 75 Valley Stream Parkway, Suite 200, Malvern, PA 19355, USA; E-Mail: Shwet.Prakash@erm.com

2 Maryland Office, Environmental Resources Management (ERM) Inc., 200 Harry S Truman Parkway, Annapolis, MD 21401, USA; E-Mail: Carol.Young@erm.com

* Author to whom correspondence should be addressed; E-Mail: venkat.kolluru@erm.com; Tel.: +1-484-913-0393; Fax: +1-484-913-0301.

Received: 10 December 2013; in revised form: 15 February 2014 / Accepted: 5 March 2014 / Published: 1 April 2014

\begin{abstract}
Ballast water systems in large LNG carriers are essential for proper operations and stability. Water withdrawn from the surrounding environment to supply to the ballast can pose entrainment and impingement risk to the resident fish population. Quantification of these risks and the net effect on population is usually quite challenging and complex. Various methods over the last several decades have been developed and are available in the literature for quantification of entrainment of mobile and immobile lifestages of resident fish. In this study, a detailed 3-dimensional model was developed to estimate the entrainment of ichthyoplankton (fish eggs and larvae) and fish from an estuarine environment during the repeated short-term operation of a ballast water intake for an LNG carrier. It was also used to develop a zone of influence to determine the ability of mobile life stages to avoid impingement. The ichthyoplankton model is an Equivalent Adult Model (EAM) and assesses the number of breeding adults lost to the population. The EAM incorporates four different methods developed between 1978 and 2005. The study also considers the uncertainty in estimates for the lifestage data and, as such, performs sensitivity analyses to evaluate the confidence level achievable in such quantitative estimates for entrainment.
\end{abstract}


Keywords: 316(b); zone of influence; entrainment; impingement; ichthyoplankton; intakes; ballast water

\section{Introduction}

Intake systems are used throughout the world for a variety of reasons including: ballast water systems, cooling water systems, drinking water systems and industrial use systems. In all of these intake systems, water is withdrawn from the surrounding surface waters and can entrain ichthyoplankton (IP) and other life stages. Quantification of entrainment and the resulting effect on a population is usually quite challenging and complex. Various methods over the last several decades have been developed and are available in the literature for quantification of entrainment of mobile and immobile lifestages of resident fish. However, accurate estimation relies heavily on field sampling, understanding of the fish population and the choice of appropriate methodologies. Due to the differences in volitional movement, planktonic stages must be evaluated differently than swimming life stages.

Typically the risks to fishes associated with intake operations can be categorized into the following main impacts:

- Change in local circulation

- Entrainment of planktonic organisms

- Entrainment and impingement of mobile organisms

- Mortality of entrained or impinged organisms

- Effects on the population

Figure 1 shows a conceptual model of the various capture zones.

Figure 1. Conceptual model of capture zones for planktonic and mobile life stages.

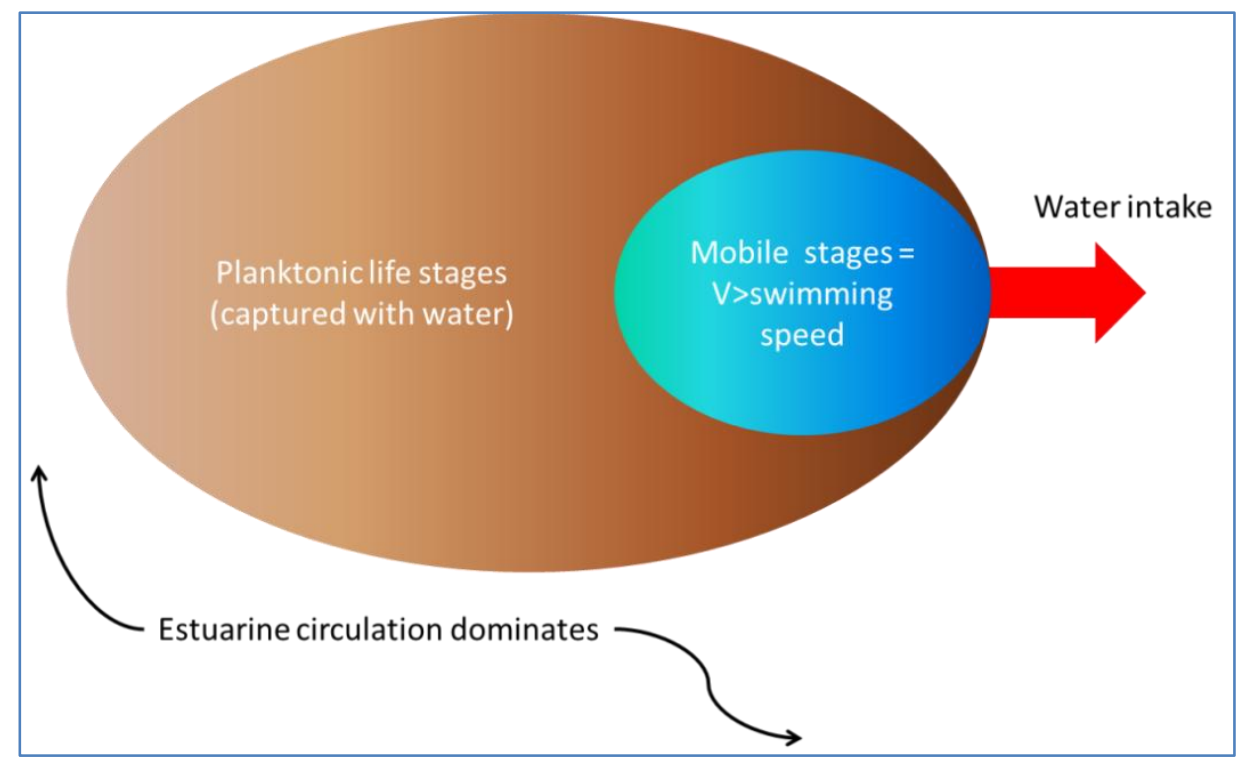




\section{Objectives}

Environmental impacts from the operations of intakes have been studied throughout the literature. The literature, however, does not include a comparison of the impact assessment methods. The objectives of this paper are:

- evaluation of intake zones of influence using a hydrodynamic model;

- comparison of literature methods for fish population impact assessment; and

- development of tools that will:

○ assist with design of intakes

$\circ$ delineate zone of influences

$\bigcirc$ quantify impacts

While impingement risk was assessed for the case study discussed here, this paper focuses on the entrainment element. Entrainment was considered in two different contexts: (1) entrainment of non-mobile IP based on concentrations in the water column and (2) entrainment of mobile life stages based on a zone of influence and burst swimming speeds. Since the ballast water along with any entrained organisms is removed from the area by the vessel, entrainment mortality was assumed to be $100 \%$.

To accomplish these objectives, two 3-dimensional models were used. The first 3-dimensional model was used to develop the flow fields and was based on Delft3D [1,2]. The second model was based on Generalized Environmental Modeling System for surface waters [3-5] and was used to estimate the entrainment of IP from an estuarine environment during the short-term operation of a ballast water intake for an LNG carrier. The equivalent adult model (GEMSS-EAM) assesses the equivalent adults lost through entrainment of ichthyoplankton using the modeled flow fields and incorporates four different methods developed between 1978 and 2005. These methods stem from the same approach of considering lifestages, lifestage durations, natural mortalities related to planktonic lifestages and entrainment mortalities attributable to the intake operations. The study also considers the potential for juveniles and adults to become entrained based on their swimming ability relative to the zone of influence at the intake. The study also considers the uncertainty in estimates for the lifestage data and, as such, performs sensitivity analyses to evaluate the confidence level achievable in such quantitative estimates for entrainment.

For mobile life stages, the focus was on the endangered shortnose sturgeon (Acipenser brevirostrum) and the protected (due to its similar appearance) Atlantic sturgeon (Acipenser oxyrhynchus). The second element of the analysis considered the burst swimming speeds of adults and juveniles and their ability to escape either impingement (larger adults) or entrainment (smaller adults and juveniles).

All entrainment calculations relied on a hydrodynamic model for the estuary that simulates a 3-dimensional near-field zone of influence in a tidal environment. The 3-dimensional hydrodynamic model was run to predict baseline (no intake operation) hydrodynamic conditions which were contrasted against the conditions during the intake operations. The two modeled conditions were quantitatively compared and the resulting changes in the hydrodynamic conditions were calculated. For plankton, the model was used to predict the number of each species group and planktonic life stage entrained as a function of the volume of water and concentration of IP by species group and life stage. 
This analysis was then introduced to an Equivalent Adult Model (EAM) to project the number of adults lost to the population. For mobile life stages, the changes were quantitatively compared against swimming speeds for shortnose sturgeon (Acipenser brevirostrum) and Atlantic sturgeon (Acipenser oxyrhynchus). Sustained, prolonged and burst speeds were considered during evaluation of effects of the intake zone of influence on these species and their ability to escape entrainment.

\section{Equivalent Adult Model (EAM)}

The GEMSS-EAM model was developed by extending the Equivalent Adult Model (EAM) formulation described in Horst [6] and Goodyear [7] to include the entrainment estimates from near field regions of a surface water intake. The Goodyear EAM [7] estimates the numbers of adult fish that would result based on the early life-stage population. EAM estimates the loss of IP vulnerable to intake system withdrawals based on the fraction of water volume drawn from various areas throughout the range of vulnerability multiplied by the density of vulnerable IP in those areas. The analysis allows direct comparison of what mortality occurs as a result of fish losses due to entrainment and impingement, compared to populations in the area. From this point, the IP losses are projected to equivalent adults using four methods available in the literature:

Method 1. Extension of the Horst [6] and Goodyear [7] methods to near-field entrainment estimates;

Method 2. Adjustment of the Horst [6] and Goodyear [7] based estimates to consider natural mortality;

Method 3. Adjustment using a survival function developed by EPRI [8]; and

Method 4. Adjustment using a survival function published by Exponent [9].

These methods provide a range of projected equivalent losses which can be used to assess the impacts of intake operations.

The hydrodynamic and entrainment modeling is used as input densities of IP from the field sampling data from the sampling regions. The density of a species for a given life-stage " $\mathrm{j}$ " at the intake during week " $i$ " is defined mathematically as $\mathrm{DW}_{\mathrm{i}, \mathrm{j}}$. If $\mathrm{D}_{\mathrm{i}, \mathrm{j}, \mathrm{k}}$ is the density of the same species for life stage " $\mathrm{j}$ " and in region " $k$ " during week "i", then its density at the intake becomes:

$$
D W_{i, j}=\sum_{k} D_{i, j, k} E_{i, k} / E_{o i, k}
$$

Where $\mathrm{E}_{\mathrm{i}, \mathrm{k}} / \mathrm{E}_{\mathrm{Oi}, \mathrm{k}}$ is the fraction of density entrained from a sampling region to the initial sampling region density. The sampling density is population density which is the number of organisms per $1000 \mathrm{ft}^{3}$ of water and is defined individually for each species, lifestage, region and week. Thus, using the parameters computed from the hydrodynamic and transport model, the intake density required for performing the entrainment analysis leading to the EAM evaluation, $\mathrm{DW}_{\mathrm{i}, \mathrm{j}}$ can be estimated from the observed densities, $D_{i, j, k}$ in all sampling regions, weighted by the fractional entrainment from that region.

\subsection{EAM Modeling from Biological Sampling Region Data}

Placing the fractional loss of IP data into context is difficult, largely due to incomplete knowledge of the total population of vulnerable life stages available, their period of vulnerability within each age class or life stage (to the point where they are mobile and can avoid the effects of entrainment or 
impingement), or their mortality through the system (assumed to be 100\%: all entrained IP are lost). The model calculates the portion lost due to entrainment based on the hydrodynamic modeling and the population of vulnerable IP throughout the area potentially affected by the water withdrawals. The identification of vulnerable IP population was based on the extent of the withdrawal modeled by the hydrodynamic model.

Having calculated the number of IP lost, the next task is to place that loss into some context, such as the equivalent number of adults lost to the system, as a result of losses at each life stage (day-age-class, cohort, etc.). There are two methods to complete that analysis, either estimating the population of adults that loss would have represented by forecasting the numbers of adults that would have resulted from the population of earlier lifestages by cascading throughout successive lifestages to the adult stage, or estimating the stock size from which those numbers derived in the first place by hind-casting losses of IP into adults that would have produced that number of those life stages or age-classes of fish. Forecasting the loss of adults applies some estimate of survival to adulthood for each life stage, which itself is subject to debate. We address the former, using the EAM tool.

For a species, the number of equivalent adults entrained can be expressed mathematically as:

$$
N a=\sum_{j=1}^{n} N_{j} S_{j}^{n}
$$

where $N_{j}$ is the number of individuals at life stage (or age class) " $\mathrm{j}$ " that have been entrained, $S^{n}{ }_{j}$ is the survival probability from the jth life stage class to adulthood, and " $n$ " is the total number of life stages before reaching adulthood. Equation (2) can be expanded to give the number of organisms entrained from each sampling region for each weekly set of observed densities, or $N_{i, j, k}$. It can be computed as:

$$
N_{i, j, k}=D_{i, j, k} S_{j}^{n} V_{i, k} F E_{i, k}
$$

where $F E_{i, k}$ is the fraction entrained from region "k", and is computed from the hydrodynamic and transport model as:

$$
F E_{i, k}=E_{i, k} / E_{o i, k}
$$

The net equivalent adults entrained, $\mathrm{Na}$, from all the regions and over the entire simulation period, then, is:

$$
N a=\sum_{i} \sum_{j} \sum_{k} N_{i, j, k}
$$

Expanding Equation (5) using Equations (3) and (4) gives:

$$
\text { Method 1: } N a=\sum_{i} \sum_{k}\left\{\sum_{j} D_{i, j, k} S_{j}^{n}\right\} F E_{i, k} V_{i, k}
$$

This formulation of the EAM, with application over several sampling regions, using weekly density data and results from the hydrodynamic model provides a necessary and important refinement to its computation as recommended by Horst [6]. 


\subsection{Determination of the Probability of Survival $S_{j}$}

An important part of the EAM model is the estimation of natural survival rate, $S_{j}$. The original Goodyear [7] paper uses a complex method based on fecundity and cumulative catch data segregated into separate length classes. Others have segregated the data into day-age classes, cohorts (groups of fish spawned within a similar time frame or of like age) or life stages (yolk-sac or prolarvae, post yolk-sac larvae, juveniles, etc.).

Another method, and one used locally in the Salem PSEG 316(b) demonstration as part of their NPDES permit application report [10], is to compute $S_{j}$ from the mortality rate of each successive life stage through to the adult stage. A limitation of this approach is the varying efficiencies of sampling used to estimate populations of successive lifestages of species, but the survival through an individual life stage can be computed as:

$$
f_{l}=\exp ^{-z_{l} T_{l}}
$$

where $f_{l}$ is the probability of survival through life stage $l$ (fraction survived at the end of the life stage), and $l=$ an index for the individual life stage; e.g., $l=1$ is eggs, $l=2$ is larvae, $l=3$ is juveniles etc. The $z_{l}$ is the natural mortality rate (1/day) for life stage $l$, and $T_{l}$ is the length (days) of life stage $l . S_{j}^{n}$ the product of the probability of survival from life stage $l$ through all successive life stages to the adult life stage, then can be given by:

$$
S_{j}^{n}=\prod_{l=j}^{n} f_{l}
$$

where " $n$ " is the final life stage. Equation (8) can also be written as:

$$
S_{j}^{n}=\exp ^{\sum_{l=j}^{n}-z_{l} T_{l}}
$$

The sum within Equation (9) goes from life stage $\mathrm{j}$ through all life stages to the adult stage, $\mathrm{n}$, even though entrainment does not take place beyond a certain life stage. This varies by species, but was assumed to be through the post-yolk larval stage. For the computations in Equation (6) only the densities up through the entrainable life stages should be used.

\subsection{Percent of Population Entrained}

Entrainment impact assessment compares the number of fishes entrained through and lost to the intake against the population at risk. A common limitation in extrapolating the IP losses to equivalent adults in many of these analyses is the lack of good fisheries data for the broader system feeding IP into the region potentially affected by the intake. In fact, locally, comments made in the Salem report [10] were that the EAM was not used extensively because there were no fishery data or other information available for comparative purposes. This limitation can be overcome, in part, using the extended model with weekly regional sampling. Examination of Equation (6) shows that the adult population within the sampled regions that could have survived in the absence of the entrainment from the ballast intake over the different life stages is: 


$$
N a_{T}=\sum_{i} \sum_{k}\left\{\sum_{j} D_{i, j, k} S_{j}^{n}\right\} V_{i, k}
$$

Thus, the percent entrainment of equivalent adults from the full population of adults that might have been entrained from those regions becomes:

$$
\% \text { Entrained }=\mathrm{Na} / \mathrm{Na}_{\mathrm{T}} * 100
$$

The percent entrained is determined only from the potential adults that could have been entrained from the surveyed regions, and not to the total fisheries population produced for the whole waterbody that may include un-sampled regions. Thus, in that case, Equation (11) will give a larger percentage entrained than if the total fisheries of the whole waterbody (entire waterbody sampled) population were known.

\subsection{Entrainment Mortality}

The above formulation includes the implicit assumption that all the species are entrained at the beginning of the life stage, in that it does not account for natural mortality that occurs on that life stage. This assumption, however, is invalid per se, as both the natural mortality and entrainment mortality occur simultaneously. The assumption of all the entrainment occurring at the beginning of the life stage is therefore conservative; it overestimates the effect of entrainment mortality on the population by not accounting for the natural mortality that would have reduced that same population over the period for which they were entrained. To decrease this overestimate, an entrainment function is required. This entrainment function depends on the entrainment mortality.

Entrainment mortality is defined as the rate of entrainment from each region due to the intake operations and is treated similar to the natural mortality. For instance, if there is no natural mortality, then the survival rate for species can be estimated by a formula similar to the one given by Equation (9). Equation (12) below shows the entrainment mortality which depends only on the intake operations and the regional hydrodynamics.

$$
\text { Entrainmen } t \text { Mortality }=\frac{Q_{I n}}{V_{T}}
$$

where $Q_{I n}$ is the intake flow rate and $V_{T}$ is the total volume of the waterbody disturbed. In cases where the waterbody is divided in to " $\mathrm{k}$ " regions, the entrainment mortality is given by Equation (13).

$$
\text { Entrainmen t Mortality }=\frac{Q_{l n}}{V_{k}} * F_{i, k}=m_{i, k}
$$

where $F_{i, k}$ is defined as the ratio of the number of individuals entrained at the intake from region "k" during week $\mathrm{i}$ to the total number of individuals entrained from all regions and is shown in Equation (14).

$$
F_{i, k}=\frac{E_{i, k}}{E_{T i}}
$$

The survival function due to the entrainment is then given by Equation (15). 


$$
S_{i, j, k}^{m}=\exp ^{\sum_{l=j}^{n}-m_{i, k} T_{l}}
$$

The number of equivalent adults entrained then can be expressed by Equation (16).

$$
\text { Method 2: } N a=\sum_{i} \sum_{k}\left\{\sum_{j} D_{i, j, k} S_{j}^{m}\left(1-S_{j}^{m}\right)\right\} F E_{i, k} V_{i, k}
$$

\subsection{EPRI Adjusted Entrainment Survival Function}

The above formulation applies the entrainment mortality at the end of the life stage, and thus has tendency to under-predict the entrained population. When day-age class population size and survival functions by day-age class are unavailable, the Electric Power Research Institute [8] suggests that the entrainment mortality should be applied assuming that half the natural mortality has occurred (e.g., the middle of the life stage). At this point, the IP population at each life stage has decreased due to the natural mortality and thus more accurately attributes losses due to entrainment. When the entrainment mortality is applied at this half-life-stage, the survival function due to entrainment is given by EPRI [8]:

$$
S_{i, k}^{*}=2 * S_{j}^{n} * \exp ^{-\left(1+\ln \left(S^{n}\right)\right)}
$$

The number of equivalent adults entrained then can be expressed by Equation (18).

$$
\text { Method 3: } N a=\sum_{i} \sum_{k}\left\{\sum_{j} D_{i, j, k} S_{j}^{n}\left(1-S^{*}{ }_{j}\right)\right\} F E_{i, k} V_{i, k}
$$

\subsection{Exponent, Inc.-Adjusted Entrainment Survival Function}

Exponent, Inc. was commissioned by the Center for Liquefied Natural Gas (CLNG) to investigate and critique the technical work adopted to estimate the entrainment impacts in Open Loop Vaporization (OLV) systems, which were commonly proposed in warmer open water (offshore) LNG revaporization designs. Exponent, Inc. found that the assumption of half natural mortality used in EPRI's method still makes the entrainment mortality conservative since the natural mortality survival function is an exponentially decreasing term. This results in an overestimation of the entrainment impacts. To further improve the entrainment survival function, Exponent, Inc. suggested an alternate relationship which defines the survival function at the end of each life stage as given by Equation (19) [9]:

$$
S^{* *}{ }_{i, k}=\frac{S_{j}^{n}\left\{\frac{S_{i, k}^{m}}{m}+T_{l}-\frac{1}{m}\right\}}{S_{j}^{n} * S_{i, k}^{m}\left\{\frac{1}{k+m}-\frac{1}{k * S_{j}^{n}}\right\}-\left\{\frac{1}{k+m}-\frac{1}{k}\right\}}
$$

The survival function is continuous within each stage as opposed to at the half-life stage. This further corrects the estimate of survivability by discretizing the continuous effects of natural and 
entrainment mortality into smaller steps (life stages). The number of equivalent adults entrained then can be expressed by Equation (20).

$$
\text { Method 4: } N a=\sum_{i} \sum_{k}\left\{\sum_{j} D_{i, j, k} S_{j}^{n}\left(1-S^{* *}{ }_{j}\right)\right\} F E_{i, k} V_{i, k}
$$

\section{Case Study}

The case study used to demonstrate the entrainment computations and study the possible fish population-level impacts is vessel ballasting in an estuarine system. The site is located in the Delaware River Estuary where concerns were raised about the potential negative effects on the population of ichthyoplankton from entrainment during ballast water intake at the terminal berth and also the entrainment risk to sturgeon presented by the ballast intake. A $138,000 \mathrm{~m}^{3} \mathrm{LNG}$ carrier, the design vessel for this study, will withdraw approximately 8 million gallons [11] of ballast water while at berth. The operations assume that one LNG carrier will call at the project every two to three days, resulting in approximately 150 ship calls per year or 12 per month. For the purposes of this study, the design intake rate of 660,430 gallons per hour and the design reballasting period of $12 \mathrm{~h}$ were selected. Figure 2 shows the site location in New Jersey near the state lines of Pennsylvania and Delaware.

Figure 2. Site location.

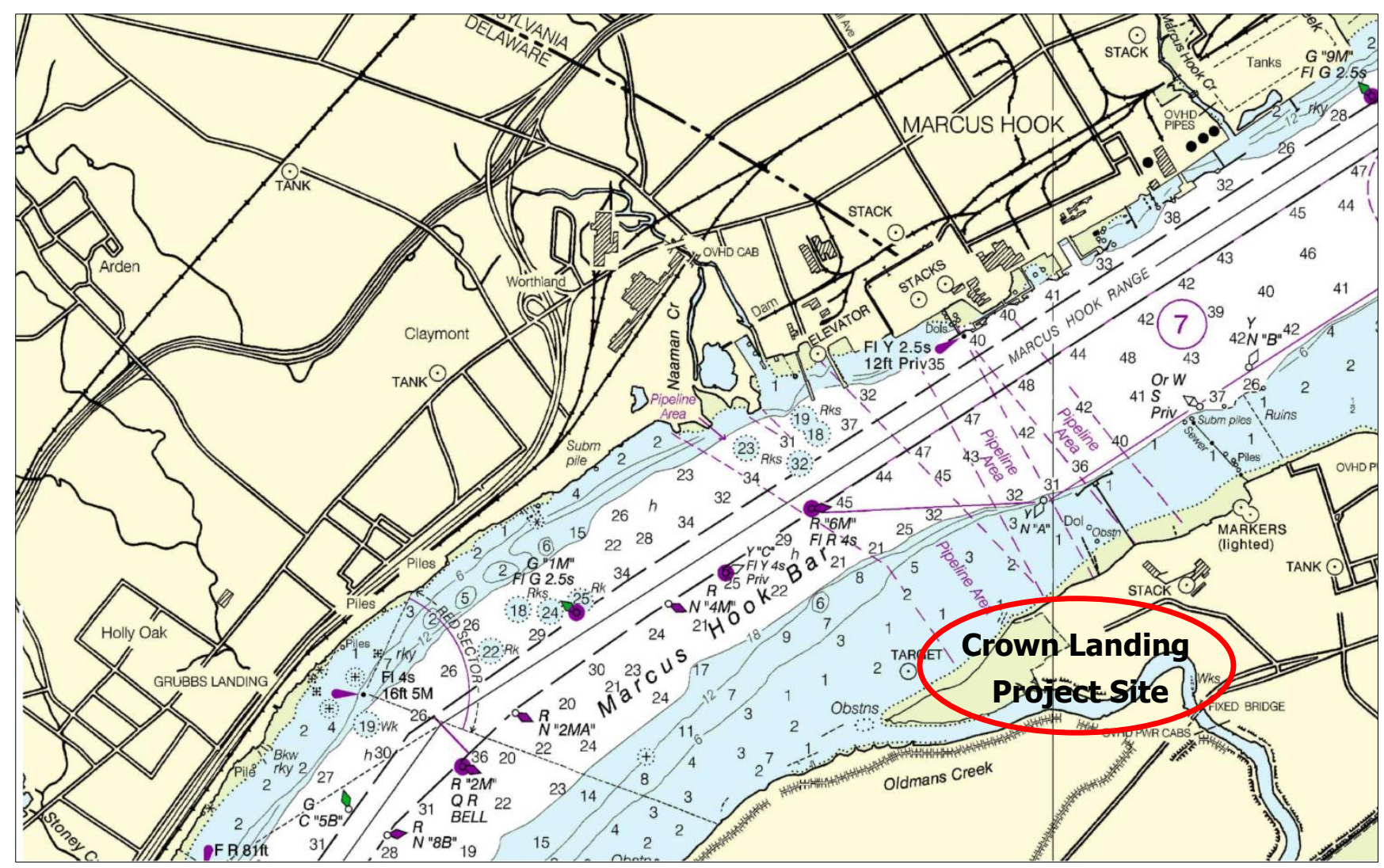




\subsection{Ichthyoplankton}

Striped bass, white perch, clupeidae (river herring and American shad), and bay anchovy were the species and groups of concern since they consistently dominate the IP population in the project area. Mean IP densities between the months of April and July were available for the Delaware River in the project area. These density data were collected by PSEG during the springs of 2002 [12] and 2003 [13]. The density data were separated into different zones along the length of the Delaware River and, for purposes of this case study, it was assumed that these densities did not vary vertically and were composites of all trawls in each zone; however, the hydrodynamic model was divided into three vertical zones: epilimnion, metalimnion and hypolimnion. Only four zones (8-11) around the import terminal were considered as they covered a region of 25 miles downstream and 30 miles upstream (see Figure 3). The entrainable population within these four zones is shown in Table 1. IP is assumed to be present only during the months of April through July, so annual losses are calculated as a sum of these four months.

Figure 3. Project location and IP data zones.

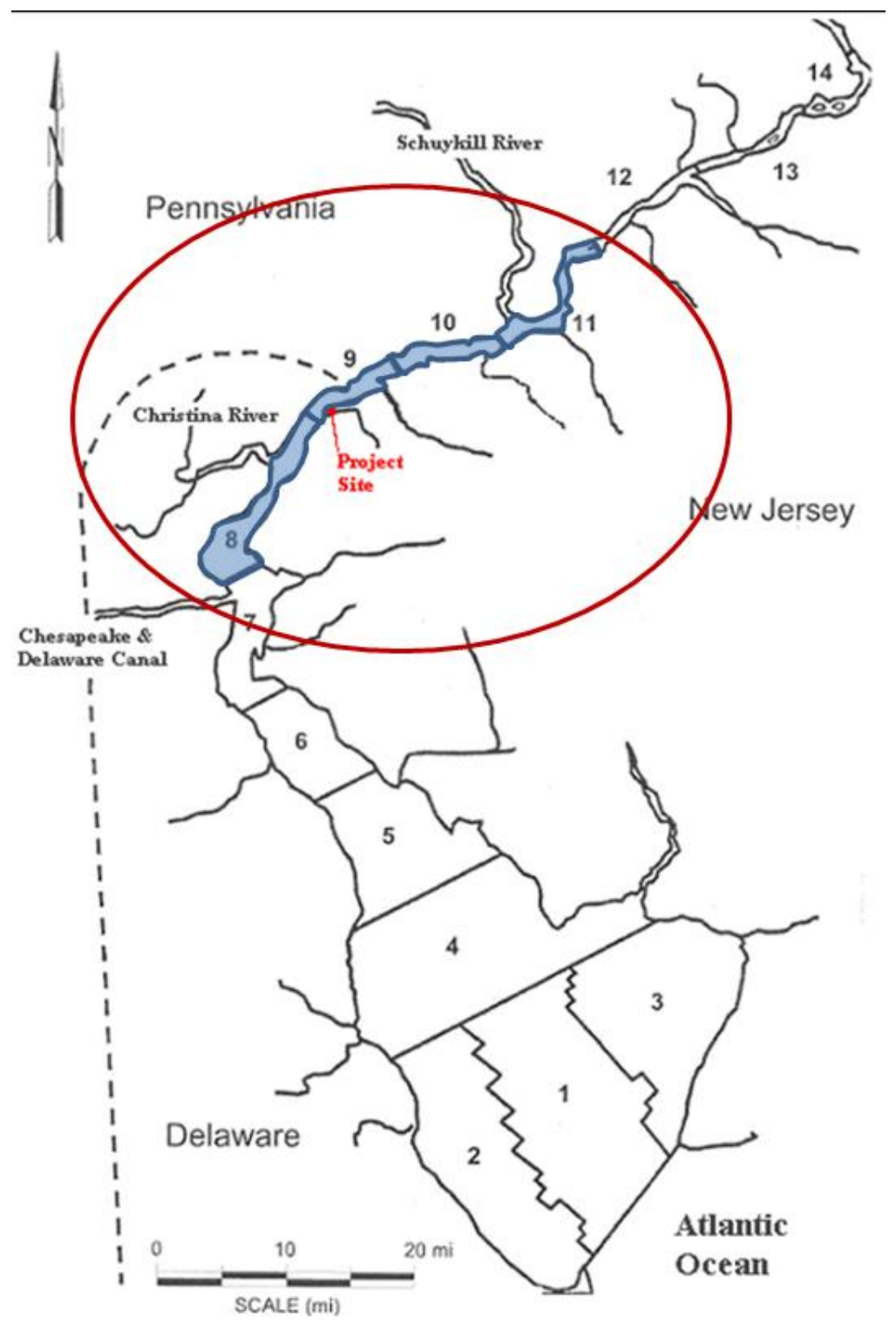


Table 1. Entrainable IP by PSEG zone (number of organisms per $1000 \mathrm{ft}^{3}$ of water).

\begin{tabular}{cccccc}
\hline Species/Group & Life Stage & Zone 8 & Zone 9 & Zone 10 & Zone 11 \\
\hline Clupeidae & Egg & 0.00 & 0.06 & 0.14 & 1.39 \\
(American Shad & Prolarvae & 0.00 & 0.51 & 1.64 & 8.92 \\
and River Herring) & Postlarvae & 5.18 & 8.61 & 9.86 & 12.57 \\
& Egg & 0.00 & 0.00 & 0.00 & 0.00 \\
Bay Anchovy & Prolarvae & 0.00 & 0.00 & 0.00 & 0.00 \\
& Postlarvae & 72.13 & 0.57 & 0.03 & 0.00 \\
& Egg & 0.03 & 1.16 & 0.91 & 1.36 \\
White Perch & Prolarvae & 0.65 & 0.76 & 1.19 & 3.34 \\
& Postlarvae & 156.87 & 10.17 & 16.17 & 23.25 \\
& Egg & 31.44 & 41.4 & 1.05 & 0.54 \\
Striped Bass & Prolarvae & 27.90 & 21.75 & 0.88 & 0.17 \\
& Postlarvae & 938.00 & 5.8 & 7.1 & 0.86 \\
\hline
\end{tabular}

Figure 4. Ballast intake extent of influence.

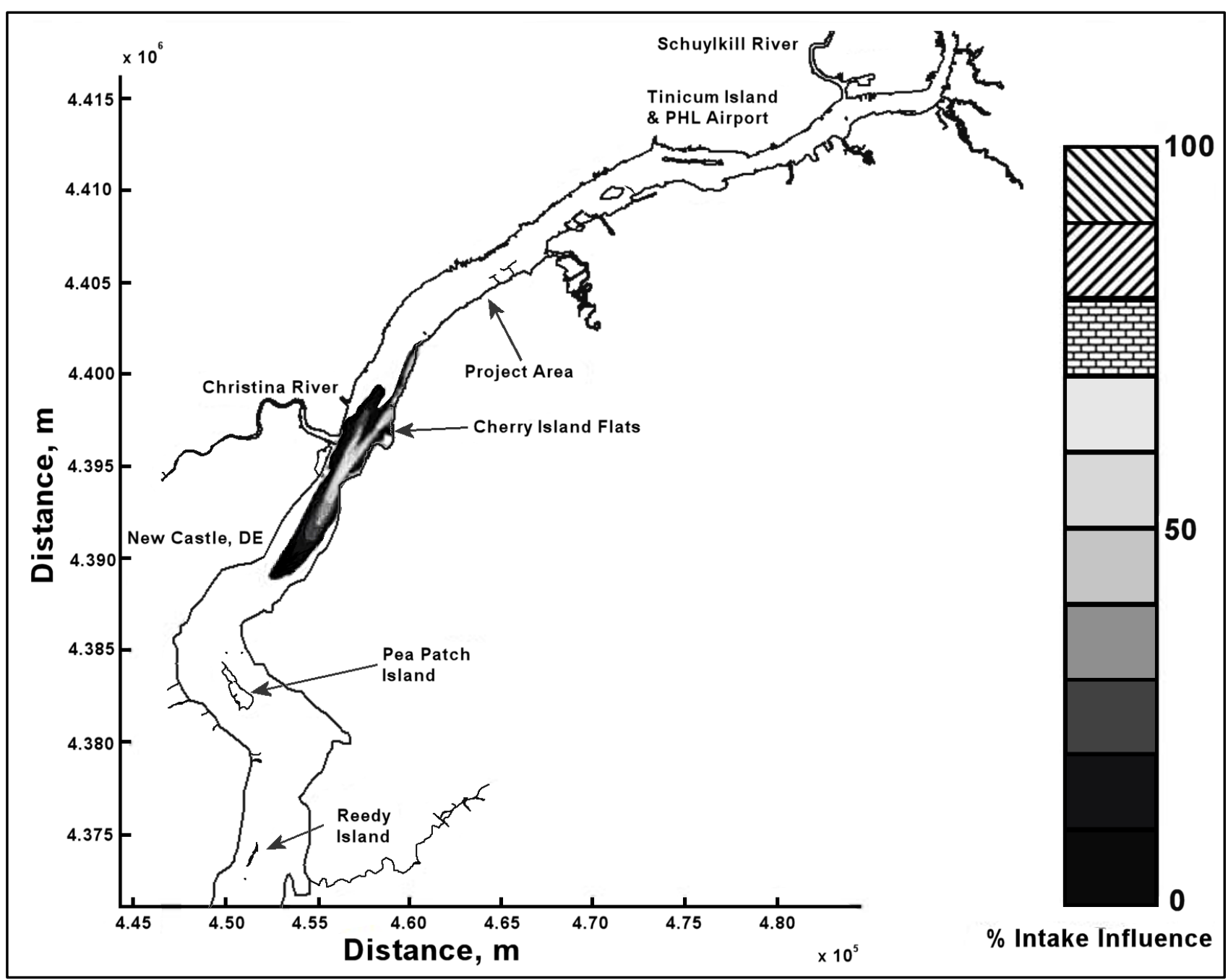

A hydrodynamic model and a water quality transport model were developed to evaluate the percentage of water entrained during a single ballast water intake at the project location. The numerical modeling protocol established in Edinger and Kolluru [14] to estimate the entrainment of 
ichthyoplankton due to power plant cooling water intakes along a body of water was used as the basis for this study. Edinger and Kolluru divided the domain into several regions and used a numerical hydrodynamic model and a numerical transport model to simulate the entrainment of dye from each of these regions. The dye does not react or decay. The percentage of the dye entrained is used as a proxy to represent the amount of ichthyoplankton entrained. The model was based on the Delft3D [1,2] modeling system. The grid was created around the LNG terminal with grid sizes varying between $50 \mathrm{~m}$ and $200 \mathrm{~m}$ in the $x$-direction (along the river) and $65 \mathrm{~m}$ and $100 \mathrm{~m}$ in the $y$-direction (across the river). The grid extends all the way down to the Delaware Bay on the southern side and to Philadelphia on the northern side with 21,669 surface cells. The vertical resolution of the grid is chosen as $1 \mathrm{~m}$. The model was run under flood and ebb conditions at the import terminal. Figure 4 shows the extent of influence of the ballast intake as modeled.

The percentage of water entrained during each ballast water intake cycle during the flood condition is shown in Table 2.

Table 2. Percent of each water layer entrained by ballasting — flood condition.

\begin{tabular}{|c|c|c|c|}
\hline Zone/Month & $\begin{array}{l}\text { Percent Entrained } \\
\text { from Epilimnion }\end{array}$ & $\begin{array}{l}\text { Percent Entrained } \\
\text { from Metalimnion }\end{array}$ & $\begin{array}{l}\text { Percent Entrained } \\
\text { from Hypolimnion }\end{array}$ \\
\hline \multicolumn{4}{|c|}{ April } \\
\hline Zone 8 & $0.000 \%$ & $0.000 \%$ & $0.000 \%$ \\
\hline Zone 9 & $0.033 \%$ & $0.012 \%$ & $0.017 \%$ \\
\hline Zone 10 & $0.002 \%$ & $0.002 \%$ & $0.002 \%$ \\
\hline Zone 11 & $0.000 \%$ & $0.000 \%$ & $0.000 \%$ \\
\hline \multicolumn{4}{|c|}{ May } \\
\hline Zone 8 & $0.000 \%$ & $0.000 \%$ & $0.000 \%$ \\
\hline Zone 9 & $0.034 \%$ & $0.012 \%$ & $0.018 \%$ \\
\hline Zone 10 & $0.002 \%$ & $0.001 \%$ & $0.001 \%$ \\
\hline Zone 11 & $0.000 \%$ & $0.000 \%$ & $0.000 \%$ \\
\hline \multicolumn{4}{|c|}{ June } \\
\hline Zone 8 & $0.000 \%$ & $0.000 \%$ & $0.000 \%$ \\
\hline Zone 9 & $0.034 \%$ & $0.012 \%$ & $0.017 \%$ \\
\hline Zone 10 & $0.001 \%$ & $0.001 \%$ & $0.001 \%$ \\
\hline Zone 11 & $0.000 \%$ & $0.000 \%$ & $0.000 \%$ \\
\hline \multicolumn{4}{|c|}{ July } \\
\hline Zone 8 & $0.000 \%$ & $0.000 \%$ & $0.000 \%$ \\
\hline Zone 9 & $0.035 \%$ & $0.012 \%$ & $0.017 \%$ \\
\hline Zone 10 & $0.001 \%$ & $0.001 \%$ & $0.001 \%$ \\
\hline Zone 11 & $0.000 \%$ & $0.000 \%$ & $0.000 \%$ \\
\hline
\end{tabular}

These percentages were further used to estimate the entrainment potential for the four species based on their lifestage duration and natural mortality as shown in Tables 3 and 4 . 
Table 3. IP stage durations.

\begin{tabular}{cccc}
\hline Species/Group & \multicolumn{3}{c}{ Lifespan in Each Life Stage (Days) } \\
\cline { 2 - 4 } & Egg & Yolk Sac Larvae & Post-Yolk Sac Larvae \\
\hline White Perch & 3 & 30 & 332 \\
Clupeidae & 6 & 53 & 306 \\
Striped Bass & 2 & 52 & 311 \\
Bay Anchovy & 1 & 34 & 330 \\
\hline
\end{tabular}

Table 4. Natural mortality rates.

\begin{tabular}{cccc}
\hline \multirow{2}{*}{ Species/Group } & \multicolumn{3}{c}{ Natural Mortality in Each Life Stage $\left(\right.$ Day $\left.^{\mathbf{- 1}}\right)$} \\
\cline { 2 - 4 } & Egg & Yolk Sac Larvae & Post-Yolk Sac Larvae \\
\hline White Perch & 0.601 & 0.164 & 0.005 \\
Clupeidae & 0.088 & 0.065 & 0.020 \\
Striped Bass & 0.601 & 0.164 & 0.005 \\
Bay Anchovy & 0.648 & 0.202 & 0.004 \\
\hline
\end{tabular}

Overlaying the water capture fraction with the IP densities, life stage durations and natural mortality, the EAM model can calculate the effective entrainment. All four methods described previously were examined to compare the predictions of the different methods. Table 5 summarizes the results and shows the predicted number of equivalent adults lost annually due to the intake operations. Methods 1 and 2 provide estimates of the likely upper and lower bound of the adults lost, while Methods 3 and 4 tend to give results reflective of the actual numbers likely to be lost. Table 6 shows the equivalent number of adults lost as a percentage of total equivalent adults available within the entrainable zone. The projected number of adults lost are very small (maximum of $0.12 \%$ ) and thus suggest that the intake operations will likely have very little effect on the regional fish populations, if any.

Table 5. Total number of equivalent adults lost annually during flood and ebb condition ballast water intake operations using the four equivalent adult methods available in GEMSS-EAM.

\begin{tabular}{ccccc}
\hline Species/Group & Method 1 & Method 2 & Method 3 & Method 4 \\
\hline & \multicolumn{4}{c}{ Flood Condition } \\
Clupeidae & 478 & 89 & 476 & 459 \\
Bay anchovy & 7472 & 1133 & 4245 & 2869 \\
White perch & 13,706 & 1325 & 9485 & 6618 \\
Striped bass & 30,671 & 5725 & 20,324 & 14,120 \\
& & Ebb Condition & & \\
Clupeidae & 360 & 55 & 357 & 344 \\
Bay anchovy & 16,425 & 994 & 9330 & 6270 \\
White perch & 15,454 & 1817 & 10,695 & 7473 \\
Striped bass & 110,427 & 3594 & 73,166 & 50,327 \\
\hline
\end{tabular}


Table 6. Total number of equivalent adults lost annually as percentage of total equivalent adults available in the entrainable zone (average of flood and ebb condition).

\begin{tabular}{ccccc}
\hline Species/Group & Method 1 & Method 2 & Method 3 & Method 4 \\
\hline Clupeidae & $0.01 \%$ & $0.00 \%$ & $0.01 \%$ & $0.01 \%$ \\
Bay anchovy & $0.00 \%$ & $0.00 \%$ & $0.00 \%$ & $0.00 \%$ \\
White perch & $0.00 \%$ & $0.00 \%$ & $0.00 \%$ & $0.00 \%$ \\
Striped bass & $0.12 \%$ & $0.02 \%$ & $0.08 \%$ & $0.05 \%$ \\
\hline
\end{tabular}

The Methods 1 and 2 are clearly bounding approaches because Method 1 applies the entrainment mortality at the beginning of the life stage (largest population size within the life stage) whereas Method 2 applies entrainment mortality at the end of the life stage (smallest population size within the life stage). These two assumptions lead to Method 1 over predicting and Method 2 under predicting the actual losses. The remaining two models attempt to apply the entrainment mortality at a more reasonable point (within the life stage). Method 3 uses the midpoint of the life stage whereas Method 4 applies it continuously along with the entrainment mortality (net mortality which is a result of exponentially decaying population from entrainment and natural mortality individually). It is therefore important to bind the estimated impacts using these approaches along with considering the Method 4 as a more realistic estimate.

\subsection{Zone of Influence-Sturgeon Effects}

To address sturgeon entrainment, the zone of influence from the operation of the ballast water intake was studied using a second hydrodynamic model, GEMSS (Generalized Environmental Modeling System for Surface waters). A second model was applied to capture the level of detail required to evaluate the active swimming of fish as opposed to the passive entrainment of IP. The first step of the modeling was to create a high resolution near field grid around the ballast intake. The high resolution grid was created around this intake location with grid sizes varying between $10 \mathrm{~m}$ and $250 \mathrm{~m}$ in the $x$-direction (along the river) and $15 \mathrm{~m}$ and $300 \mathrm{~m}$ in the $y$-direction (across the river). The grid extends about $1 \mathrm{~km}$ on either side of the terminal along the river and covers the entire cross section with 1850 surface cells. The vertical resolution of the grid is chosen as $0.5 \mathrm{~m}$. Based on the design information, the ballast intake of diameter $0.6 \mathrm{~m}(600 \mathrm{~mm})$ and location of $3.7 \mathrm{~m}$ above the keel and $57 \mathrm{~m}$ forward of the stern was assumed. The high resolution model did not separate the two tidal cases as with the low resolution model earlier. The entire tidal cycle was combined into one model simulation to obtain cumulative effects. Some adults are long enough to become impinged if captured sidelong across the intake. Other mobile stages (adults and juveniles) can become entrained due to size or body orientation when they encounter the intake. These intake dimensions were closely followed in setting up the LNG carrier in the model domain as shown in Figure 5. 
Figure 5. Carrier representation on the model domain.

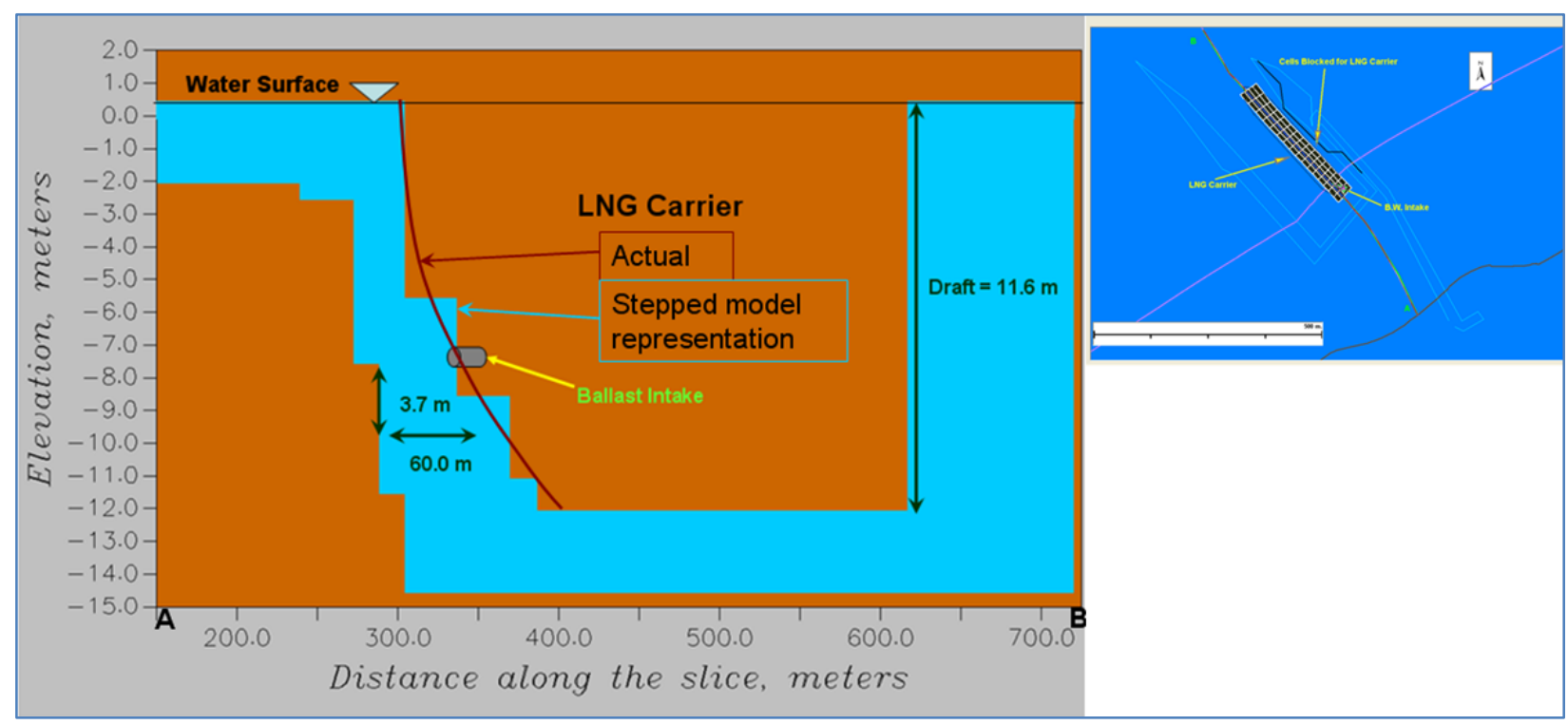

Shortnose sturgeon have typical mean swimming speeds of $8.1 \mathrm{~cm} / \mathrm{s}$ to $34.0 \mathrm{~cm} / \mathrm{s}$. These swimming speeds (and also burst speeds) are size dependent [15]. McCleave [16] found that the mean swimming speeds for shortnose sturgeon vary between 0.07 and 0.37 body lengths/s. Limited information is available about the swimming speeds for Atlantic sturgeon. Shortnose sturgeons are endangered species due the historical fishing and Atlantic sturgeon are similarly protected due to their resemblance to the shortnose. Entrainment of these sturgeons due to intake operations in the Delaware River is of concern. Sturgeons, and other species, as well can attain peak swimming speeds of up to 10-22 lengths/s [15] under increased opposing flows. However, during these increased swimming speeds (burst speed), respiration increases which results in exhaustion decreasing the distance traveled. Thus, they are expected to escape high flow conditions if the zone of this high flow is less than their endurance. The swimming speeds for these sturgeons were obtained from Amaral and Sullivan [17] and are summarized in Table 7.

Table 7. Swimming speeds.

\begin{tabular}{cccc}
\hline Swimming/Speed Type & Sustained Duration & Speed & Fish Length \\
\hline Maximum Sustained & $>200 \mathrm{~min}$ & $4 \mathrm{~cm} / \mathrm{s}$ & $15 \mathrm{~cm}$ \\
Speeds & & $84 \mathrm{~cm} / \mathrm{s}$ & $120 \mathrm{~cm}$ \\
Prolonged Speeds & $20 \mathrm{~s}-200 \mathrm{~min}$ & $39 \mathrm{~cm} / \mathrm{s}$ & $16 \mathrm{~cm}$ \\
& & $90 \mathrm{~cm} / \mathrm{s}$ & $120 \mathrm{~cm}$ \\
& & $90 \mathrm{~cm} / \mathrm{s}$ & $45 \mathrm{~cm}$ \\
Burst Speeds & $<20 \mathrm{~s}$ & Same as Prolonged & Same as Prolonged \\
\hline
\end{tabular}

The ballast water intake was located at a depth as shown in Figure 5. The high resolution model was run for two cases. Case 01 was run with the intake turned on whereas the Case 02 was run without the intake. These two cases were needed to determine the change in hydrodynamic conditions attributable to the intake operations. At this depth, in the near field, the horizontal velocity was predominantly towards the intake. There is a drastic difference in the horizontal velocities between the two cases. To 
better understand the effects due to the intake operation alone, consider Figure 6, which shows the velocity difference (with intake-without intake). The difference was very high close to the intake $(\sim 35 \mathrm{~cm} / \mathrm{s})$ but this difference rapidly decreased with distance from the intake.

Figure 6. Horizontal velocities at intake for each case.

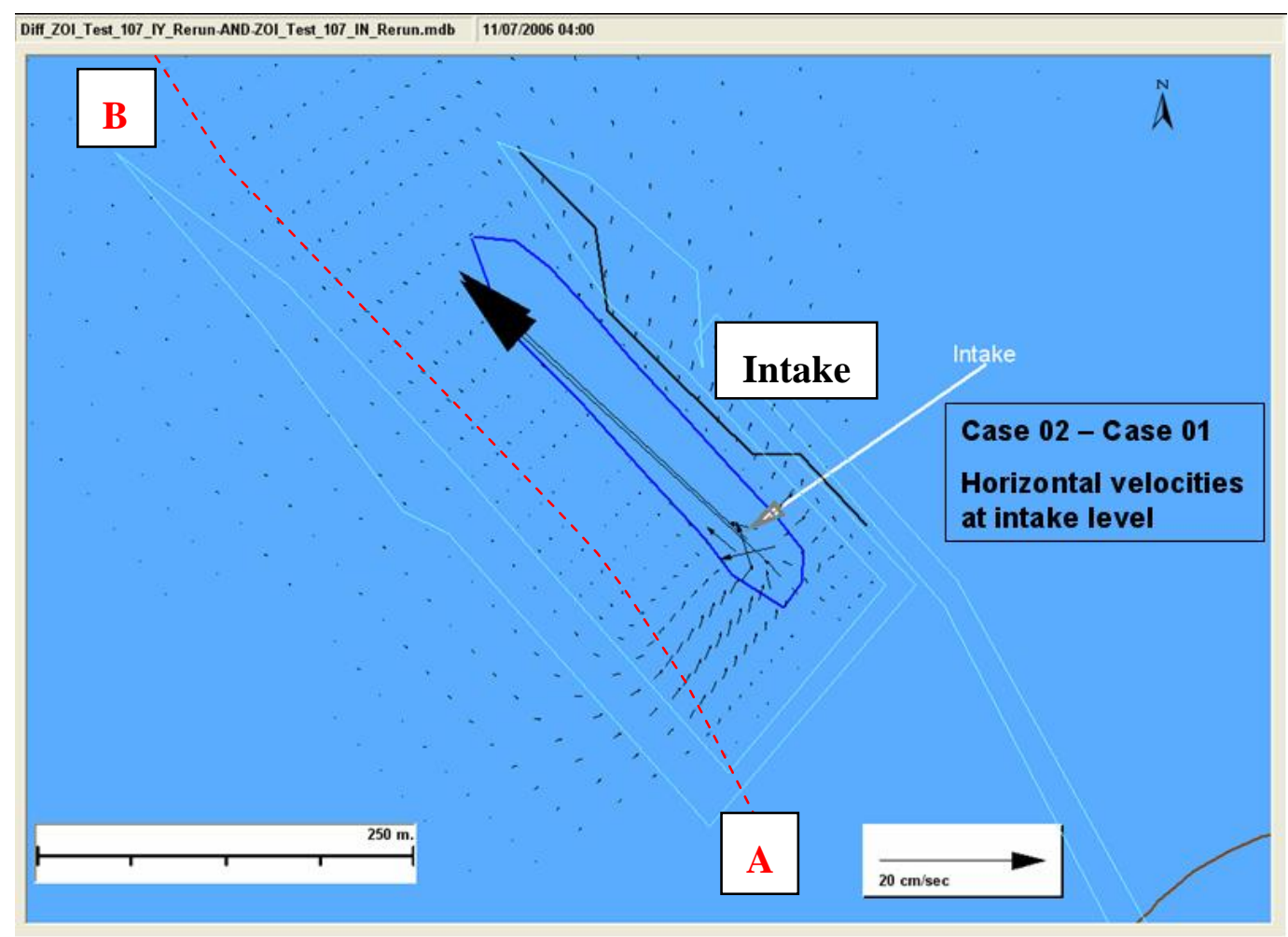

A northwest-southeast plane (Slice $\mathrm{AB}$ ) passing through the ballast water intake, as shown in Figures 5 and 6, was chosen to study the vertical and northwest-southeast directional flow and zone of influence. The hydrodynamics of the region close to the intake is mostly dominated by the intake momentum as compared to the tidal influence. As we move slightly away from this region a small tidal variation in the circulation is seen under different tidal phases. The difference in the flow conditions between the two cases is shown in Figure 7. The flows are high and directed towards the intake with a defined circulatory flow pattern. The effects of the intake, though smaller, can be seen even close to the bottom ( $6 \mathrm{~m}$ below the intake). The difference in the velocity magnitude between the two cases is as high as $50 \mathrm{~cm} / \mathrm{s}$ (Figure 7). The differential velocity vectors clearly show a new eddy type circulation pattern introduced during the up estuary flow condition. The incremental velocity magnitude close to the bottom ranges between $0.5 \mathrm{~cm} / \mathrm{s}$ and $6 \mathrm{~cm} / \mathrm{s}$. The zone of influence is about $5 \mathrm{~m}-6 \mathrm{~m}$ in the vertical direction and about $50 \mathrm{~m}$ in the horizontal direction. After around $50 \mathrm{~m}$ in the horizontal direction at the intake level, the difference in net velocity magnitude drops to $0.1 \%$ $(<0.5 \mathrm{~cm} / \mathrm{s}$ as compared to $50 \mathrm{~cm} / \mathrm{s}$ at the intake cell). 
Figure 7. Differential velocities.

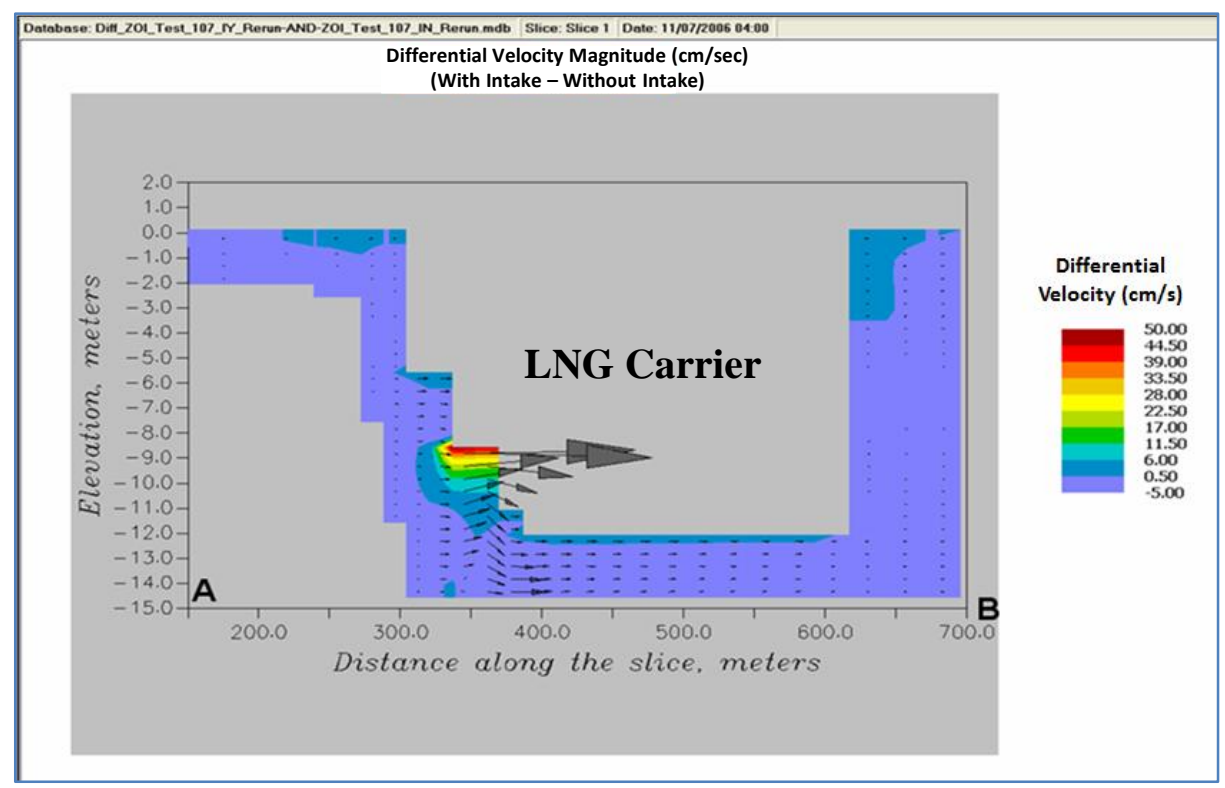

The mouth of the intake experiences the maximum increased flow (increase of $30-50 \mathrm{~cm} / \mathrm{s}$ ) which results in similar intake velocities of $30-50 \mathrm{~cm} / \mathrm{s}$ (Figure 8 ). These velocities at the intake when the ballast water intake is active are within the mean swimming speeds of both Atlantic and shortnose sturgeon. The burst speeds are much higher than the intake velocities and thus can allow them to escape the zone of influence. The burst swimming speeds cannot be sustained for a long duration (Table 7). However, at these speeds (e.g., $90 \mathrm{~cm} / \mathrm{s})$ fish can move up to $18 \mathrm{~m}(90 \mathrm{~cm} / \mathrm{s} \times 20 \mathrm{~s})$ to $54 \mathrm{~m}$ $(90 \mathrm{~cm} / \mathrm{s} \times 60 \mathrm{~s})$ which will move them out of the zone of influence $(50 \mathrm{~m})$. Even though the burst swimming speeds are not sustainable, the extent of the zone of influence is small to allow the fish to quickly escape. However, there may be instances when the fish are close to the intake and may be entrained due to the smaller net velocity (swimming speed-velocity towards intake). Only a volume of $13 \mathrm{~m}^{3}$ was above the lowest burst swimming speed of $40 \mathrm{~cm} / \mathrm{s}$, a very small region.

Figure 8. Velocity magnitude when intake is active.

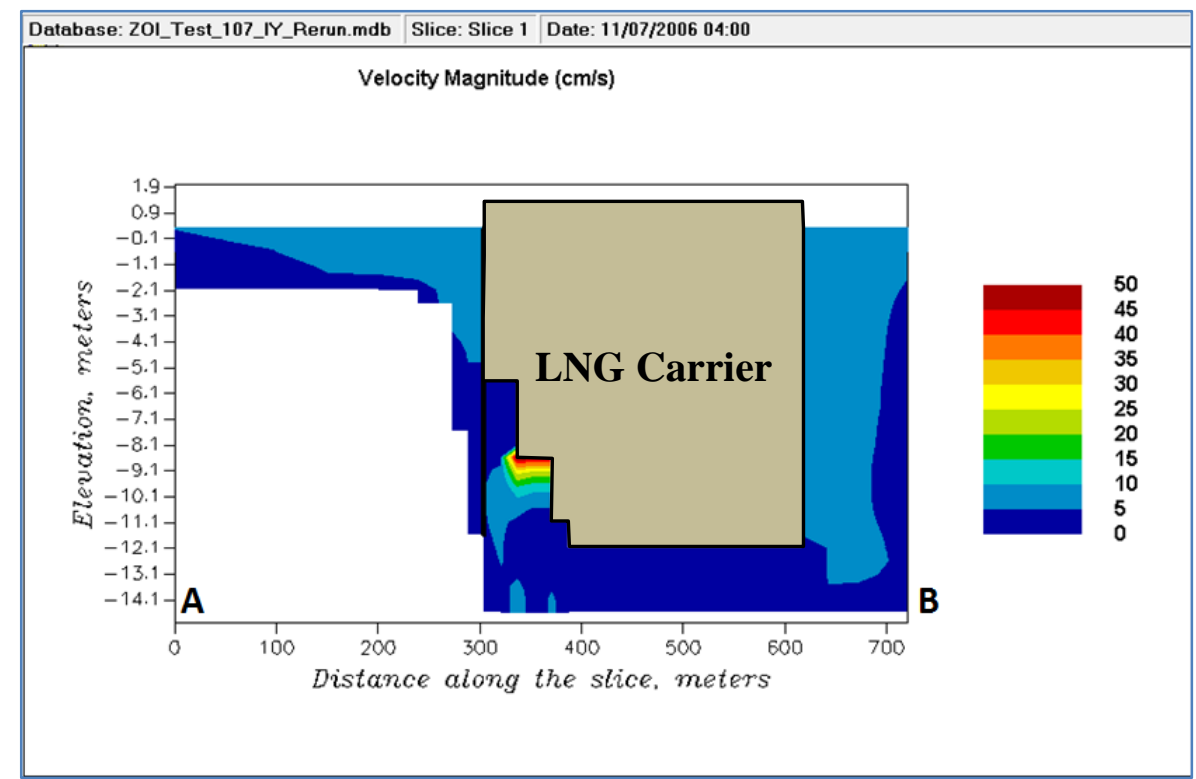




\section{Summary and Conclusions}

\subsection{Ichthyoplankton and Equivalent Adults}

Using these data, the GEMSS-EAM was run for each of the four months in question (April, May, June and July), assuming all ballast intake occurs while the ship is at berth. Methods 1 and 2 provide estimates of the likely upper and lower bound of the adults lost, while Methods 3 and 4 tend to give results reflective of the actual numbers likely to be lost. The projected numbers of adults lost are very small (maximum of $0.12 \%$ ) and thus suggest that the intake operations will likely have very little effect on the regional fish populations. Use of all four methods provides confirmation bounds for these quantifications that rely heavily on lifestage information which is hard to predict. A range of equivalent adults lost, therefore, is an appropriate choice. Additionally, sensitivity analysis should be performed to assess the uncertainty potential of these estimates.

It should be noted that there is always some risk associated with the withdrawal of ballast water by the ship intake. An expectation of no risk should not be a criterion for evaluating such impacts as the ecosystem, under natural conditions, has the ability to recover from small impacts. The risk evaluation completed as part of the study shows that the impacts are minimal, and within the ecosystem's ability to recover from.

\subsection{Sturgeon Effects}

The velocity at the mouth of the intake was calculated as $30-50 \mathrm{~cm} / \mathrm{s}$. These velocities are within the mean swimming speeds of both Atlantic and shortnose sturgeon. The burst speeds are much higher than the intake velocities and thus can allow them to escape the zone of influence. At these speeds (e.g., $90 \mathrm{~cm} / \mathrm{s}$ ), fish can swim up to $18-54 \mathrm{~m}$, which will move them out of the zone of influence $(50 \mathrm{~m})$. Even though the burst swimming speeds are not sustainable, the extent of the zone of influence is small to allow the fish to quickly escape. Only a volume of $13 \mathrm{~m}^{3}$ was above the lowest burst swimming speed of $40 \mathrm{~cm} / \mathrm{s}$.

\section{Acknowledgments}

The authors would like to thank BP America for providing the necessary funding for this study. Authors also acknowledge the resources and encouragement provided by Environmental Resource Management (ERM) to develop these formulations.

\section{Author Contributions}

Shwet Prakash, Venkat S. Kolluru and Carol Young conceptualized the model formulations and development. Shwet Prakash developed coding for various formulations; Venkat Kolluru developed the hydrodynamic model and provided technical direction throughout the project. Carol Young managed the overall project.

\section{Conflicts of Interest}

The authors declare no conflict of interest. 


\section{References and Notes}

1. Delft. Delft3D-FLOW: Simulation of Multi-Dimensional Hydrodynamic Flows and Transport Phenomena, Including Sediments; WL | Delft Hydraulics: Delft, The Netherlands, 2004.

2. Delft. Delft3D-RGFGRID: Generation and Manipulation of Curvilinear Grids for FLOW and WAVE User Manual; WL | Delft Hydraulics: Delft, The Netherlands, 2004.

3. Edinger, J.E.; Buchak, E.M. Numerical Hydrodynamics of Estuaries in Estuarine and Wetland Processes with Emphasis on Modeling; Hamilton, P., Macdonald, K.B., Eds.; Plenum Press: New York, NY, USA, 1980; pp. 115-146.

4. Kolluru, V.S.; Buchak, E.M.; Edinger, J.E. Integrated Model to Simulate the Transport and Fate of Mine Tailings in Deep Waters. In Proceedings of the Tailings and Mine Waste '98 Conference, Fort Collins, CO, USA, 26-29 January 1998.

5. Prakash, S.; Kolluru, V.S. Implementation of Higher Order Transport Schemes with Explicit and Implicit Formulations in a 3-D Hydrodynamic and Transport Model. In Proceedings of 7th International Conference on Hydroscience and Engineering, Philadelphia, PA, USA, 10-13 September 2006.

6. Horst, T.J. The Equivalent Adult Model: A General Model for Fisheries Impact Assessment; Environmental Division, Stone \& Webster Engineering Corporation: Boston, MA, USA, 1977.

7. Goodyear, C.P. Entrainment Impact Estimates Using the Equivalent Adult Approach; Department of Interior, Fish and Wildlife Service, Office of Biological Services, Power Plant Project: Minneapolis and Saint Paul, MN, USA, 1978.

8. Electric Power Research Institute (EPRI). Extrapolating Impingement and Entrainment Losses to Equivalent Adults and Production Foregone; Document No. 1008471; EPRI: Palo Alto, CA, USA, 2004.

9. Nielsen, R.D.; Ginn, T.C.; Ziccardi, L.M.; Boehm, P.D. An Evaluation of the Approaches Used to Predict Potential Impacts of Open Loop LNG Vaporization Systems on Fishery Resources of the Gulf of Mexico; Document No. BN02922.001 01F1 1005 DN21; Centre for liquefied natural Gas, Seawater Usage Technology Committee: Washington, DC, USA, November 2005.

10. Public Service Electric and Gas Company (PSEG). Salem Generating Station Permit Application to New Jersey Department of Environmental Protection; PSEG: Salem, NJ, USA, 1999.

11. The value was provided by BP and relates to different density between $\mathrm{LNG}\left(450 \mathrm{~kg} / \mathrm{m}^{3}\right)$ and seawater density $\left(1027 \mathrm{~kg} / \mathrm{m}^{3}\right)$ and the remaining ballast water would be taken on as the vessel departs and after exiting the most sensitive habitat area. In consultation with both vessel captains and resource agencies, $8 \mathrm{mg}$ of ballast was selected as the ballast volume for this analysis.

12. Public Service Electric and Gas Company. Ichthyoplankton Sampling Study Data Report for 2002; PSEG: Salem, NJ, USA, 2002.

13. Public Service Electric and Gas Company. Ichthyoplankton Sampling Study Data Report for 2003; PSEG: Salem, NJ, USA, 2003.

14. Edinger, J.E.; Kolluru, V.S. Power Plant Intake Entrainment Analysis. J. Energy Eng. 2000, 126, $1-14$.

15. Castro-Santos, T.; Haro, A. Sprinting Performance of Upstream Migratory Fishes; Conte Anadromous Fish Research Center/USGS-BRD: Turners Falls, MA, USA, 2000. 
16. McCleave, J.D.; Fried, S.M.; Towt, A.K. Daily movements of shortnose sturgeon, Acipenser brevirostrum, in a Maine estuary. Copeia 1977, 1977, 149-157.

17. Amaral, S.; Sullivan, T. Downstream Fish Passage from Sturgeon. In Proceedings of Great Lakes Sturgeon Coordination Meeting, Sault Ste. Marie, MI, USA, 9-10 November 2004.

(C) 2014 by the authors; licensee MDPI, Basel, Switzerland. This article is an open access article distributed under the terms and conditions of the Creative Commons Attribution license (http://creativecommons.org/licenses/by/3.0/). 